\title{
Case 2: Abdominal Distention in a Term Infant with Unilateral Ventriculomegaly
}

\author{
Allison N. J. Lyle and Bobbi J. Byrne
}

An early term female neonate is born at 37 weeks, 2 days of gestation with a birthweight of $3.1 \mathrm{~kg}$. She is delivered vaginally by a 26 -year-old woman after induction of labor for preeclampsia with severe features; magnesium sulfate was given during labor. Prenatal history is significant for late prenatal care (14 weeks) and fetal diagnosis of right-sided ventriculomegaly noted on serial ultrasonography, first at 20 weeks of gestation and confirmed on fetal magnetic resonance imaging (MRI) at 27 weeks. All prenatal serologic findings were negative, a 1-hour oral glucose tolerance test result was within normal limits, and cell-free fetal DNA was negative for trisomies 13, 18, and 21. Maternal-fetal medicine, neonatal-perinatal medicine, and pediatric neurosurgical physician teams were involved in the prenatal care, and a plan was developed to admit the infant to the level III NICU after birth for further brain imaging.

At delivery, the infant is vigorous, with Apgar scores of 9 and 9 at 1 and 5 minutes, respectively. Birthweight is at the 50th percentile, length is greater than the 97th percentile, and occipitofrontal circumference is at the 90 th percentile. The remainder of the newborn examination is unremarkable, including a perforate anus, and the infant is admitted to the NICU for known right-sided ventriculomegaly. On the day of birth, postnatal MRI demonstrates asymmetric right-sided ventriculomegaly likely secondary to a prior germinal matrix and intraventricular hemorrhage. The infant feeds orally and voids normally but no stools are noted. At birth, a chromosomal microarray is obtained, which later reveals a likely benign duplication at 7q21.12-q21.13, with no known clinical significance associated.

This is the author's manuscript of the work published in final form as:

Lyle, A. N. J., \& Byrne, B. J. (2019). Case 2: Abdominal Distention in a Term Infant with Unilateral Ventriculomegaly. NeoReviews, 20(10), e594-e596. https://doi.org/10.1542/neo.20-10-e594 
On the day after birth, the infant develops abdominal distention with decreased bowel sounds and lethargy. Oral feeding is discontinued and intravenous fluids are initiated. Vital signs are stable and examination findings are otherwise unremarkable, with no respiratory distress noted in room air. Voiding remains normal, but again, no stools are noted.

\section{Case Progression}

A kidney, ureter, bladder (KUB) radiograph was obtained, which demonstrated mildly dilated loops of bowel throughout the abdomen. The infant was given nothing by mouth, and a Replogle tube was placed for abdominal decompression. Intravenous antibiotics (ampicillin and gentamicin) were started after performing a sepsis screen. The complete blood cell count and C-reactive protein levels were unremarkable. A repeat KUB radiograph remained concerning for a small bowel obstruction (Fig 1), and the infant developed bilious output from the appropriately positioned Replogle tube. A water-soluble contrast enema was performed on the third day, which revealed multiple intraluminal filling defects and meconium plugging (Fig 2). Shortly after the contrast enema, the infant began to pass stools, with 5 largevolume meconium stools noted in the following 24 hours. Abdominal distention and gastric output decreased, and a repeat KUB radiograph demonstrated decreased gaseous distention. Oral feedings were reinitiated 2 days after the enema and were advanced without difficulty. Daily occipitofrontal circumference measurements remained stable throughout the infant's hospitalization. She was discharged from the hospital on the 7th day after birth, voiding and stooling appropriately, and with follow-up scheduled with the neurosurgical team to continue to monitor the stable ventriculomegaly.

\section{Discussion}

The differential diagnosis of abdominal distention in a newborn includes volvulus (with or without malrotation), necrotizing enterocolitis, sepsis, Hirschsprung disease, meconium syndromes (such as ileus or plug), intestinal webs or atresias, hypertrophic pyloric stenosis, congenital microcolon, spontaneous intestinal perforation, imperforate anus, peritoneal bands, internal hernias, and rarely, lactobezoars. (1)(2) 
Small left colon syndrome, first described in 1974, is thought to occur because of immaturity of the myenteric plexus ganglia (1) of the colon, which leads to a transient functional obstruction in newborns and carries a strong association with maternal diabetes mellitus, (3)(4) maternal preeclampsia treated with magnesium sulfate, (1) and prematurity. (1) Maternal diabetes mellitus, either gestational or pregestational, is the most common association, reported in $40 \%$ to $50 \%$ of the few published cases of small left colon syndrome. (3) Small left colon syndrome is the most common diagnosis in newborns who fail to pass meconium within the first 48 hours after birth. $(1)(3)(4)(5)(6)$

Abdominal radiography will demonstrate lower bowel obstruction with or without air-fluid levels. Watersoluble contrast enema is frequently both diagnostic and therapeutic in these patients, demonstrating a significant change in colonic caliber. An abrupt transition occurs at the splenic flexure to a narrow distal colon, relieving the obstruction by flushing away any meconium present in the distal colon. Normal intestinal motility without long-term complications is expected in cases of neonatal small left colon syndrome.

\section{Lessons for the Clinician}

- Delayed passage of meconium can be associated with disorders such as Hirschsprung disease; however, small left colon syndrome is the most common diagnosis.

- Small left colon syndrome carries a strong association with maternal diabetes mellitus.

- Any newborn who does not pass meconium within the first 48 hours after birth should have a prompt evaluation for obstruction, even if asymptomatic.

- Water-soluble contrast enemas are frequently both diagnostic and therapeutic in these patients.

\section{American Board of Pediatrics Neonatal-Perinatal Content Specifications}

- Identify the developmental pattern for motility of various segments of the alimentary canal.

- Know the factors that may inhibit or improve intestinal motility. 


\section{AUTHOR DISCLOSURES}

Drs Lyle and Byrne have disclosed no financial relationships relevant to this article. This commentary does not contain a discussion of an unapproved/investigative use of a commercial product/device. 


\section{References}

1. Fanaroff A, Martin R, Walsh M. Neonatal-Perinatal Medicine: Diseases of the Fetus and Infant, 10th ed. Philadelphia, PA: Saunders; 2014.

2. Aguayo P, Fraser JD, St. Peter SD, Ostlie DJ. Perforated Meckle's diverticulum in a micropremature infant and review of the literature. Pediatr Surg Int. 2009;25(6):539-541.

3. Ellis H, Kumar R, Kostyrka B. Neonatal small left colon syndrome in the offspring of diabetic mothers: an analysis of 105 children. J Pediatr Surg. 2009;44(12):2343-2346.

4. Loening-Baucke V, Kimura K. Failure to pass meconium: diagnosing neonatal intestinal obstruction. Am Fam Physician. 1999;60(7):2043-2050.

5. Davis WS, Allen RP, Favara BE, Slovis TL. Neonatal small left colon syndrome. Am J Roentgenol Radium Ther Nucl Med. 1974;120(2):322-329.

6. Nurko S. Motility of the colon and anorectum. NeoReviews. 2006;7(1):34-46. 


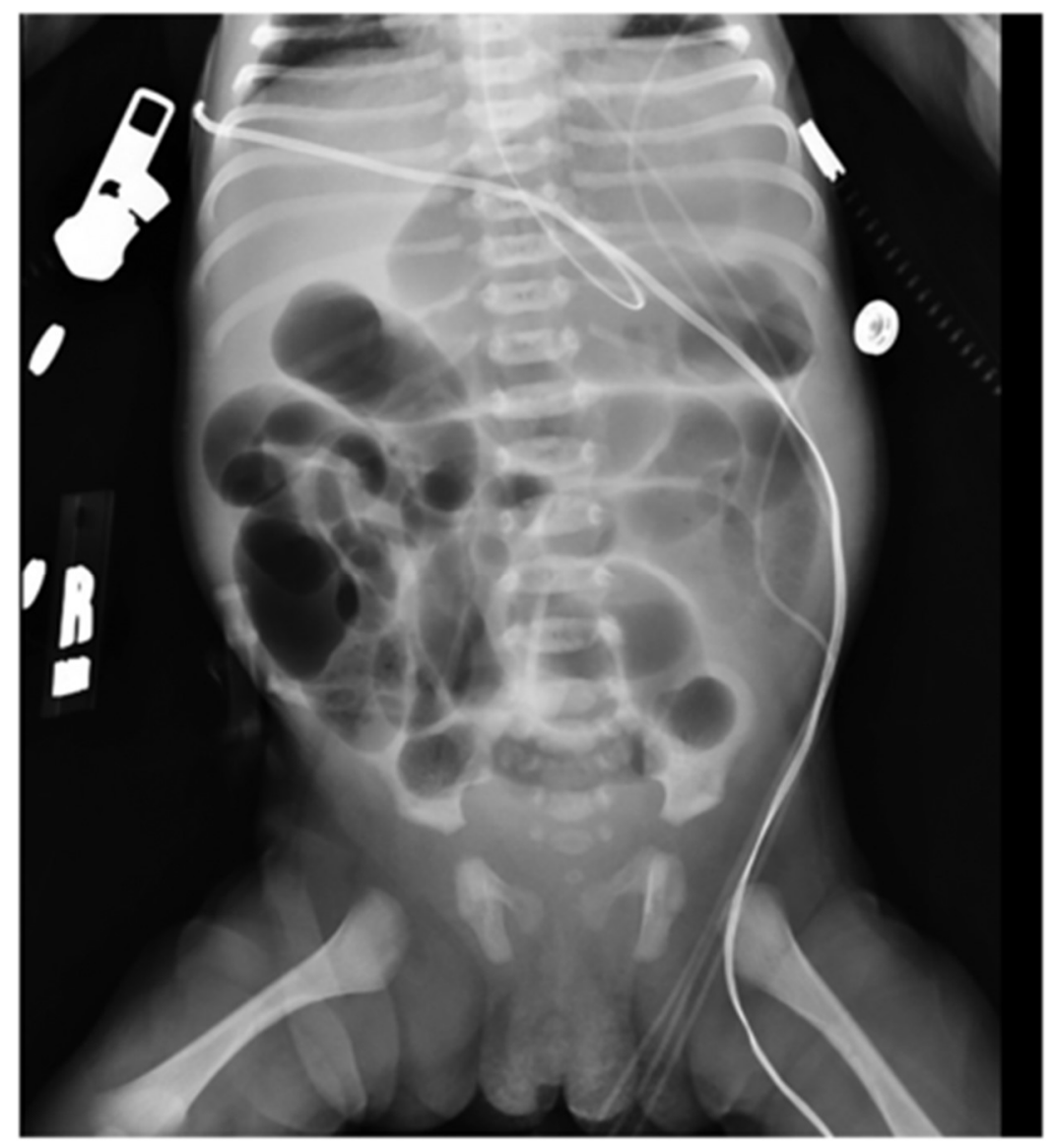

Figure 1. Small bowel obstruction noted on repeat kidney, ureter, bladder radiograph. 


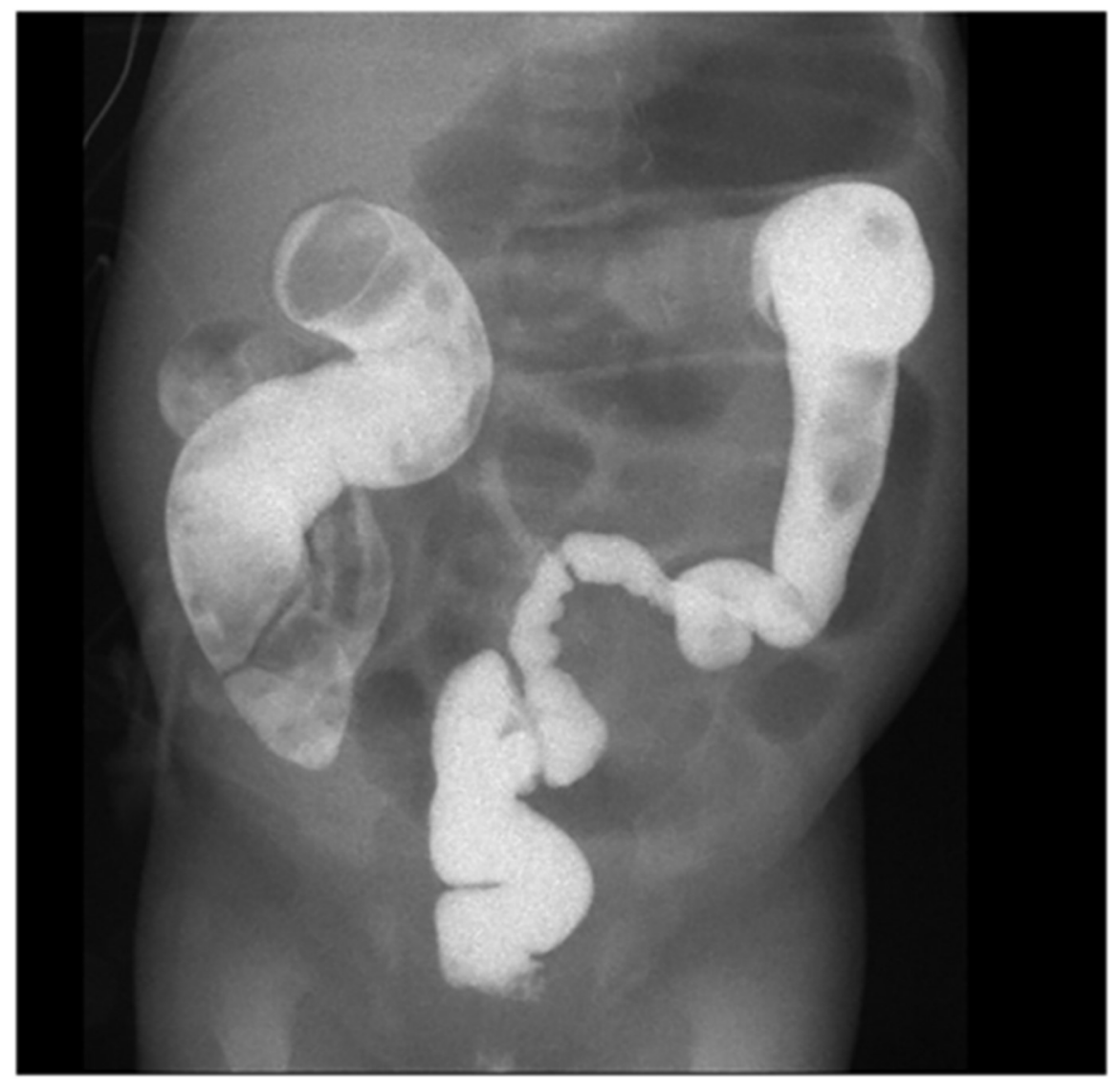

Figure 2. Multiple intraluminal filling defects and meconium plugging noted on water-soluble contrast enema. 